\title{
Koronavirüs (COVID-19) Salgın Sürecinde Evden Çalışma ile İşten Ayrılma Niyeti Arasındaki İlişkide İş Yaşamı Kalitesinin Aracı Rolü (The Mediating Role of Quality of Work Life in the Relationship between Working from Home during the Coronavirus (COVID-19) Outbreak Process and Intention to Leave)
}

\author{
Ferhat AYYILDIZ iD a Duygu İrem ÇAM ${ }^{\text {iD }}$ b Yasemin KUŞ ${ }^{\text {iD }}$ c \\ a İstanbul Üniversitesi, Edebiyat Fakültesi, Psikoloji Bölümü, İstanbul, Türkiye. ferhat.ayyildiz@istanbul.edu.tr \\ b İstanbul Üniversitesi, İstanbul, Türkiye. iremdcam@gmail.com \\ cİstanbul Ticaret Üniversitesi, İnsan ve Toplum Bilimleri Fakültesi, İstanbul, Türkiye. ybozkurt@ticaret.edu.tr
}

\begin{tabular}{l} 
MAKALE BİLGİSI \\
\hline Anahtar Kelimeler: \\
COVID-19 \\
Salgın \\
Evden çalışma \\
İş yaşamı kalitesi \\
İşten ayrılma
\end{tabular}

Gönderilme Tarihi 13 Ekim 2020 Revizyon Tarihi 27 Aralık 2020 Kabul Tarihi 2 Mart 2021

Makale Kategorisi: Araştırma Makalesi

\section{ÖZET}

Amaç - COVID-19 salgını yaşamın birçok alanını olumsuz etkilemekte ve salgına yönelik temel tedbir olan sosyal izolasyonun sağlanması amacıyla çeşitli düzenlemeler gerçekleştirilmektedir. Bu tedbirlerin ötesinde, bireylerin sağllk ve güvenlik konusundaki endişelerini giderebilmek için çalıştıkları kurumlardan da birtakım beklentileri ortaya çıkmıştır. Örgütler bu beklentilere karşılık vermek ve mevcut işgücünü korumak adına birtakım düzenlemelerde bulunmaktadır. Bu düzenlemelere bağlı olarak çalışanların bir kısmı evden çalışma sistemine geçerken bir kısmı da iş yerlerine gitmeye devam etmektedir. Bireylerin hayatında önemli bir yer tutan iş yaşamındaki bu düzenlemeler, iş dışı faaliyetlerini ve örgüte yönelik tutumlarını etkileyebilmektedir. Bu doğrultuda mevcut araştırmada salgın sürecinde evden çalışmanın işten ayrılma niyeti ile ilişkisini ve algılanan iş yaşamı kalitesinin bu ilişkiye aracılık edip etmediğini incelemek amaçlanmıştır.

Yöntem - Araştırmada ilişkisel tarama yöntemi kullanılmıştır. Araştırma verileri, kartopu örnekleme yöntemiyle ulaşılabilen ve çevrimiçi ankete katılım gösteren 292 beyaz yakalı çalışandan elde edilmiştir. Veri toplama araçları, evden çalışmaya ilişkin bilginin de alındığı Demografik Bilgi Formu, İş Yaşamı Kalitesi Ölçeği ve İşten Ayrılma Niyeti Ölçeği'nden oluşmaktadır. Veriler SPSS 21 paketinde korelasyon ve çoklu hiyerarşik doğrusal medyatör regresyon analizi ile analiz edilmiştir.

Bulgular - Yürütülen çoklu hiyerarşik doğrusal medyatör regresyon analizi sonucunda salgın sürecinde evden çalışma ile işten ayrılma niyeti arasında negatif yönlü ilişki olduğu ve algılanan iş yaşamı kalitesinin bu ilişkiye tam aracılık ettiği görülmüştür.

Tartışma - Evden çalışma düzenlemesinin, bireylerin salgın sürecinde ortaya çıkan sağlık, güvenlik ve ekonomi konularındaki temel ihtiyaçlarına cevap verdiği görünmektedir ve bu nedenle bireyler mevcut organizasyonlarında çalışmaya devam etmek istemektedir. Salgın sonrası süreçte evden çalışma sisteminin faydalarını korumak için bu sistemin bireylerin beklentileri ile örtüşmesine dikkat edilmelidir.

\begin{tabular}{ll}
\hline ARTICLE INFO & ABSTRACT \\
\hline Keywords: & $\begin{array}{l}\text { Purpose - The COVID-19 outbreak has a negative impact on many areas of life, so various measures } \\
\text { are taken to ensure social isolation. Beyond these measures, some expectations of employees have } \\
\text { emerged from their organizations to overcome their concerns about health and safety. Organizations } \\
\text { Outbreak }\end{array}$ \\
$\begin{array}{l}\text { Working from home } \\
\text { Quality of work life }\end{array}$ & $\begin{array}{l}\text { of the employees continue to go to workplaces, some of them have started to work from home due to } \\
\text { arrangements. The aim of the current study is to investigate the relationship between working from } \\
\text { home (WFH) during the outbreak and the intention to leave and the mediator role of perceived quality } \\
\text { of work life in this relation. }\end{array}$ \\
$\begin{array}{l}\text { Design/methodology/approach - The relational scanning method was used in the research. Snowball } \\
\text { Received 13 October 2020 }\end{array}$ & $\begin{array}{l}\text { sampling method was used to reach the participants and data were obtained from 292 white collar } \\
\text { employees who answered the online survey. Data collection tools consist of the Demographic } \\
\text { Accepted 2 March 2021 }\end{array}$ \\
$\begin{array}{l}\text { Information Form which contains information about working from home, Quality of Work Life Scale } \\
\text { and Intention to Turnover Scale. It was evaluated by correlation and multiple hierarchical linear } \\
\text { mediator regression analysis in the SPSS 21 package. }\end{array}$ \\
$\begin{array}{l}\text { Article Classification: } \\
\text { Research Article }\end{array}$
\end{tabular}

\section{Önerilen Atıf/ Suggested Citation}

Ayyıldız, F., Çam, D.İ., Kuş, Y. (2021). Koronavirüs (COVID-19) Salgın Sürecinde Evden Çalışma ile İşten Ayrılma Niyeti Arasındaki İlişkide İş Yaşamı Kalitesinin Aracı Rolü, İşletme Araştırmaları Dergisi, 13 (1), 136-149. 
Findings - The multiple hierarchical linear mediator regression analysis indicated that WFH in the outbreak process had a negative relationship with the intention to leave and perceived quality of work life mediated this relationship.

Discussion - WFH seems to respond to basic needs of individuals in health, safety and economy issues during the outbreak and thus they want to continue working in their current organizations. In order to protect the benefits of WFH in the post-outbreak process, attention should be paid to match this system with the expectations of individuals.

\section{GíRiş}

Çin'de başlayan Koronavirüs (COVID-19) salgını, farklı ülkelerde yaşayan çok sayıda insanı etkileyerek dünya üzerinde yayılınca pandemi olarak ilan edilmiştir (World Health Organization [WHO], 2020a). Bu süreçte virüsün temel yayılım yolunun kişiler arası temas olduğu göz önüne alınarak (Centers for Disease Control and Prevention [CDC], 2020), salgını kontrol altına alabilmek ve bireyleri korumak amaciyla temel tedbir olarak sosyal izolasyon önerilmektedir (WHO, 2020b). Salgın sürecinde yalnızca devlet kurumları değil özel kurumlar da aldıkları kararlarla hem çalışan sağlığını korumada hem de salgının ekonomik ve sosyal etkilerini azaltmada rol oynayabilmektedir (Homeland Security Council, 2006: 166). Salgın sürecinin çalışanlar ve örgütler açısından etkileri incelendiğinde, çalışmaya devam eden bireyler enfeksiyon kaptı̆̆ veya enfekte bir aile üyesine bakım verdiği için iş yerindeki üretkenliklerinin azalabildiği görülmektedir. Ayrıca iş ortamında enfeksiyonun yayılma riski nedeniyle iş arkadaşlarının da üretkenliği düşebilmekte, müşteriler bu kişilerle temas kurmaktan korktuğu için ticari kayıplar yaşanabilmekte ve işletme açısından değerli kişiler kaybedilebilmektedir (Farnham, 1994: 313-315). Kişilerin hasta olması, ulaşım sisteminin aksaması ve kişinin iş yerinden eve virüs taşıma riski gibi faktörler bireylerin bu süreçte iş yerine giderek çalışabilmelerini olumsuz etkilemektedir (Ives vd., 2009: 62). Mevcut salgın sürecinde iş yerlerinde yapılması gerekenlere yönelik Dünya Sağlık Örgütü (WHO, 2020c: 1-2) ve İş Güvenliği ve Sağllğı İdaresi (OSHA, 2020: 11) tarafından hazırlanan raporlarda sosyal izolasyonu sağlayabilmek amacıyla esnek çalışma saatleri ve alanlarına yönelik düzenlemeler yapılması gerektiği bildirilmektedir. Bu sayede çalışanlar arasındaki fiziksel mesafenin artması ve çalışanların ailelerindeki hasta bireylere bakım sağlayabilmesi amaçlanmaktadır.

Esnek çalışma düzenlemeleri salgın koşulları nedeniyle gereklilik haline gelmişken, örgütsel açıdan da fayda sağlayabilir. Günümüzde temel örgütsel hedeflerden biri rekabet ortamında yetenekli çalışanlarını kaybetmemektir. Esnek çalışma düzenlemelerinden biri olan ve salgın döneminde yaygın bir şekilde kullanılan evden çalışma uygulaması, çalışanların ihtiyaçlarını karşılamasına olanak sağlayarak elde tutulmalarına katkı sağlayabilir. Bu bağlamda mevcut araştırmanın amacı salgın döneminde evden çalışma, algılanan iş yaşamı kalitesi ve işten ayrılma niyeti arasındaki ilişkileri incelemektir.

\section{KAVRAMSAL ÇERÇEVE}

\subsection{Evden Çalışma}

Esnek çalışma düzenlemeleri, kişilere çalışabilecekleri yer ve zaman konusunda belirli bir ölçüde değişiklik yapabilme imkânı sağlayan örgütsel politika ve uygulamalardır (Lewis, 2003: 1). Alternatif seçeneklerin varlığının, herkese uyabilecek tek bir yaklaşımdan daha iyi olacağı; bu sayede çalışma programının özel ihtiyaçlara göre uyarlanabileceği düşünülmektedir (Apgar, 1998: 122). Bu uygulamalar arasında kısmi zamanlı çalışma, uzaktan çalışma, evden çalışma, iş paylaşımı, sıkıştırılmış çalışma haftası gibi farklı türler bulunmaktadır (Çelenk ve Atmaca, 2010: 188). Mevcut salgın sürecinin öncesinde de küresel rekabet ve telekomünikasyon alanındaki gelişmeler sonucunda geleneksel iş yapısında birtakım değişiklikler gerekli hale gelmiştir. Kurumlar, bu değişen ortam ve koşullara uyum sağlayabilmek için geleneksel olmayan iş yöntemlerini benimseyerek proaktif davranmaya özen göstermektedir (İşcan ve Naktiyok, 2005: 52). Bu uygulamaları benimseme noktasında yöneticilerin temel motivasyonu maliyetleri azaltmak, üretkenliği artırmak ve çalışanları elde tutmaktır (Apgar, 1998: 121-122). Kriz dönemlerinde ise bu iş-yaşam düzenlemeleri, kurumsal baskılara reaksiyon olarak veya ekonomik faydası maliyetlerinden daha fazla olduğu ve bunun bir sosyal sorumluluk olduğuna inanıldığı için işletmeler tarafından gerçekleştirmektedir (Been, den Dulk ve van der Lippe, 2016: 58). Çalışanlar açısından bakıldığında çift kariyerli ve tek ebeveynli hanelerin artış göstermesi nedeniyle bireylerin daha yoğun aile talepleriyle karşılaşması ve ayrıca bireylerin boş zaman aktivitelerine katılım ve konum kısıtlaması olmadan çalışma konusunda daha talepkâr olması gibi faktörlerin bu yaygınlı̆̆ teşvik ettiği görülmektedir (Golden, 2009: 242). 
Esnek çalışma düzenlemeleri hem işletmelere hem de çalışanlara avantaj sağlayan kazan-kazan stratejileridir (Avcı ve Yavuz, 2020: 40). Bu düzenlemelerinin işgücü maliyetini (Çelenk ve Atmaca, 2010: 199) ve işe devamsizlığ (Possenriede, Hassink ve Plantenga, 2014: 15; Stavrou, 2005: 935) azaltırken; örgütsel performansı (Stavrou, 2005: 935), bağlılığ1 (Choo, Desa ve Asaari, 2016: 31) ve rekabet gücünü (Çelenk ve Atmaca, 2010: 199) artırdığı ve örgütün piyasada cazip algılanmasını sağladığı (Yavuz, 1995: 29) bulunmuştur. Ayrıca çalışanlar için iş-aile çatışmasını (Choo vd., 2016: 31), iş stresini (Gajendran ve Harrison, 2007: 1533) ve tükenmeyi (Sardeshmukh, Sharma ve Golden, 2012: 202) azaltırken; iş tatminini (Gajendran ve Harrison, 2007: 1533; McNall, Masuda ve Nicklin, 2009: 75) ve bireysel performansı (Gajendran ve Harrison, 2007: 1533; Kossek, Lautsch ve Eaton, 2006: 361) artırdığı bulunmuştur. Yapılan araştırmalarda çoğunlukla esnek çalışma uygulamalarının olumlu etkilerde bulunacağı öne sürülmüş ve elde edilen sonuçlara göre bu varsayımlar desteklenmiş olsa da işe tutkunluğun azalması (Sardeshmukh vd., 2012: 202), daha fazla stres yaşanması (Song ve Gao, 2020: 2660), aile sorumlulukların artması ve iş ve aile arasındaki sınırın bulanıklaşması (Sardeshmukh vd., 2012: 202) ve dolayısıyla iş-aile çatışmasının artması (Sarbu, 2018) gibi aksi yönde sonuçlarının da olabileceği tespit edilmiştir.

Esnek çalışma düzenlemeleri arasında yaygın olarak kullanılanlar zamansal ve mekânsal açıdan esneklik sağlayanlardır. Uzaktan veya evden çalışma, işin yürütüldüğü yer nedeniyle mekânsal esnekliği ifade eder; bununla birlikte zamansal esneklik de sağlayabilir (Shockley ve Allen, 2007: 480). Modern dönemde bilgi ve iletişim teknolojileri, çalışanların bu şekilde geleneksel iş yerlerinin dışında çalışabilmesine olanak sağlamıştır (Hotopp, 2002: 311). Uzaktan çalışma, evden çalışmayı da içermekte fakat daha geniş anlamda merkez ofis dışındaki çeşitli lokasyonlardan çalışmayı içermektedir (Allen, Golden, Shockley, 2015: 42-43). Evden çalışma, esnek uygulamalar içinde en esneği olarak ifade edilmektedir (Sennett, 2010: 61). Birçok beyaz yakalı mesleğin evden de gerçekleştirilebilir olması (Shamir ve Salomon, 1985: 455), bu uygulamanın modern hayatın içine yerleşmesini sağlamıştır (Van der Lippe ve Lippényi, 2020: 384). Bakıldığında giderek yaygınlaşan evden çalışma uygulaması, mekan ve zaman sınırlarını ortadan kaldırarak bireylere kişisel ve ailevi ihtiyaçları doğrultusunda iş günlerini düzenleme imkânı sağlaması (Yavuz, 1995: 21), iş ve aile yaşamını kaynaştırması (Osnowitz, 2005: 99), ulaşım, öğle yemeği ve iş kıyafetleri gibi masrafları azaltması (İşcan ve Naktiyok, 2005: 53), işe gidip gelme süresini ortadan kaldırması ve stresin daha az olduğu bir çalışma ortamı sunması (Lazar, Osoian ve Ratiu, 2010: 204), işin yarattı̆̆ yıpranma ve tükenmeyi azaltması (Bloom, Liang, Roberts ve Ying, 2015: 200), yeni kariyer fırsatları sağlaması (Reilly, 2001: 69) ve bireyleri daha memnun ve üretken kılması (Sturgeon, 1996: 27) gibi nedenlerle çalışan bireyler açısından avantaj sağlamakta ve talep edilmektedir.

Evden çalışma uygulamasının başarılı olması ve öne sürülen faydaları sağlaması çeşitli özelliklere bağlıdır. Çalışan ve yöneticisinin bu uygulama konusunda hevesli olması, çalışma programı üzerinde uzlaşılmış olması ve belirli düzeyde özerklik sunulmuş olması, çalışanın özdisiplin gibi uygun kişilik özelliklerine sahip olması ve ev ortamının da gürültü gibi çevresel özellikler açısından uygun koşullara sahip olması uygulamanın başarıya ulaşmasında etkilidir (Hobbs ve Armstrong, 1998: 369). Ayrıca bireylerin iş ve ev alanlarını birbirinden ayırabilme yeteneği de esnek uygulamaları nasıl deneyimleyeceğini etkiler (Kossek vd., 2006: 361). Ancak mevcut pandemi döneminde evden çalışma sistemine geçen birçok kurum ve çalışan, bu geçişi plan dahilinde olmadan öneriler ve kısıtlamalar nedeniyle mecburi olarak gerçekleştirmiştir. Diğer yandan, evden çalışma sistemine geçmeden geleneksel çalışma sistemlerini sürdüren veya iş süreçlerini tamamen durduran kurumlar da bulunmaktadır. Mevcut COVID-19 salgın sürecinde yürütülen bir araştırmada evden çalışma uygulamasının çalışmayı bırakmaya kıyasla daha avantajı olduğu görülmüş; evden çalışmaya devam edenler çalışmayı bırakanlara kıyasla daha iyi psikolojik sağlık durumu bildirmişlerdir (Zhang, Wang, Rauch ve Wei, 2020: 3). Tüm bu sonuçlar, önceden işletmelere değer katan yardımcı bir uygulamayken salgın sürecinde gereklilik haline gelen evden çalışma uygulamasının bireylerin çeşitli ihtiyaçlarının karşılanmasını sağlayarak örgüte yönelik tutumlarını etkileyebileceğini göstermektedir.

\section{2. İş Yaşamı Kalitesi}

Çalışma koşulları ve iş yapıları bireylerin fiziksel, sosyal ve psikolojik iyi oluşunu belirlemekte ve diğer yaşam alanlarındaki tutum ve davranışlarını da etkilemektedir (Near, Rice ve Hunt, 1980: 420; Sinha, 2012: 32). Çünkü çalışanlar örgütlere bir dizi ihtiyaç kümesi getirir ve örgütsel üyelikleri aracilığıyla bu ihtiyaçlarını karşılamayı hedefler (Efraty ve Sirgy, 1990: 32). İş yaşamının kalitesine ilişkin yapılan tanımlamaların bu ihtiyaçlara ilişkin olduğu ancak birbirinden farklılaştığı görülür. Bu tanımlamalara göre iş yaşamı kalitesi, bir kuruluşun, çalışanların ihtiyaçlarına cevap verdiği bir süreci (Nanjundeswaraswamy ve Swamy, 2013: 202) 
veya uygun iş ve yaşam koşullarını ve çevresini ifade eder (Huang, Lawler ve Lei, 2007: 737). Diğer bir tanıma göre, bireylerin işleri sayesinde elde ettiği kaynaklar, aktiviteler ve sonuçlar aracılığıyla çeşitli ihtiyaçlarını doyurması iş yaşamı kalitesi olarak adlandırılmaktadır (Sirgy, Efraty, Siegel ve Lee, 2001: 242). İş yaşamı kalitesinin özünde, bireyleri karar verme süreçlerine dahil ederek, onlara çalışma ortamını etkileyebilme fırsatının sunulması ve ihtiyaçlarını karşılama esnekliğine sahip olmaları yer alır (Kiernan ve Knutson, 1990: 103-104). Aslında iş yaşamının kalitesi, işin tüm yönlerine dair çalışanın öznel psikolojik deneyimi olarak kavramsallaştırılır (Rintala \& Suolanen, 2005: 55). Sözü edilen tüm bu yönleriyle, çalışma yaşamı kalitesinin bireyin psikolojik, sosyal ve ekonomik iyi oluşu üzerinde önemli etkileri bulunmaktadır (Kalleberg ve Vaisey, 2005: 431). Bu nedenle, iş yeri sayesinde bireylerin sadece işlerinden değil iş dışındaki alanlardan ve yaşamın bütününden tatmin olmasını; kişisel mutluluk ve öznel iyi oluş haline sahip olmasını da içerir (Sirgy vd., 2001: 242).

İş yaşamının kalitesini etkileyen temel ihtiyaçlar sağlık ve güvenlik ihtiyaçları, ekonomik ve ailevi ihtiyaçlar, sosyal ihtiyaçlar, saygınlık ihtiyaçları, kendini gerçekleştirme ihtiyaçları, bilgi ihtiyaçları ve estetik ihtiyaçlar olarak kategorize edilebilir (Sirgy vd., 2001: 246-247). Bu ihtiyaçların karşılanması için işlerin farklı yönlerine odaklanılmaktadır. Ancak iş yaşamı kalitesini anlamak için farklı faktörleri hesaba katan çok boyutlu bir yaklaşım gerekmektedir (Kalleberg ve Vaisey, 2005: 431-432). Bu doğrultuda literatürde ele alınan faktörler çalışma ortamı, örgüt kültürü ve iklimi, ilişki ve iş birliği, eğitim ve geliştirme, ücret ve ödüller, olanaklar, iş tatmini ve iş güvenliği, çalışma özerkliği ve kaynakların yeterliliği olarak bir araya getirilmiştir (Nanjundeswaraswamy ve Swamy, 2013: 207). İş yaşamının kalitesi, bu çeşitli boyutların ayrı ayrı değerlendirilerek birleştirilmesi veya işin tüm yönleri göz önünde bulundurularak bir bütün olarak değerlendirilmesi ile ölçülmektedir (Kalleberg ve Vaisey, 2005: 432).

İş yaşamı kalitesinin sonuçları incelendiğinde örgütsel tutumlarda iyileşmeye katkı sağladığı görülmektedir. Bireylerin algıladıkları iş yaşamı kalitesi artınca iş memnuniyeti (Efraty ve Sirgy, 1990: 43-44; Turunç, Tabak, Şeşen ve Türkyılmaz, 2010), algılanan örgütsel destek (Yılmaz ve Tanrıverdi, 2017: 100), örgüt ile özdeşleşme (Efraty ve Sirgy, 1990: 43-44), motivasyon (Öztürk Çiftci ve Parlak, 2019: 705) ve örgütsel bağlllıkları da artmaktadır (Altay ve Turunç, 2018: 216; Çakır, Doğantan ve Bayar, 2018:353; Erdem, 2010: 529-530). Ayrıca çalışanlar üzerindeki bu etkileri nedeniyle örgütsel harcamaları da azaltır (Horst, Broday, Bondarick, Serpe ve Pilatti, 2014: 93). Diğer yandan, iş yaşamı kalitesindeki artış iş stresini (Turunç vd., 2010: 127), işe devamsızlığ (Demir, 2011: 462) ve örgütsel sinizmi azaltmaktadır (Yıldırım ve Ceyhan, 2020: 1180).

\section{3. İşten Ayrılma Eğilimi}

Bir örgütün uzun süreli sağlı̆̆ı ve başarısı, yetenekli çalışanlarını elde tutabilmesine bağlıdır. Müşterilerin ve çalışma arkadaşlarının memnuniyetinin sağlanması, örgütün istenilen performans düzeyine erişmesi ve yedekleme planlamalarının başarılı olması bu sayede gerçekleşir (Das ve Baruah, 2013: 8). Ayrıca giderek yükselen rekabet koşullarında örgütleri birbirinden farklılaştıran temel kaynak bu yetenekli çalışanlardır. Örgütler rekabet ortamında çalışanlarının uzmanlığına güvenirken, diğer örgütler de avantaj elde etmek için bu çalışanları cezbetmeye çalışmaktadır. Bu ortamda çalışan devir hızı oldukça yükselmiş ve çalışanları elde tutmak yöneticilerin temel endişe kaynaklarından biri olmuştur (Samuel ve Chipunza, 2009: 410).

Çalışanların işlerinden ayrılması örgütler açısından kayıplara ve istenmeyen sonuçlara yol açabilmektedir. Personellerin seçilmesi ve yetiştirilmesi sürecinde zaman, para ve personel kaynağını kullanan örgütler, yaptıkları yatırımı ve dolayısıyla çalışanlarını kaybetmek istememektedir (Altay ve Turunç, 2018: 193). Yapılan yatırımların haricinde, çalışanların ayrılmasından sonra da önemli maliyetler ortaya çıkar. Çalışanların işten ayrılması, genellikle o örgütteki deneyimleri sayesinde kazandıkları değerli bilgi ve uzmanlığın ve ayrıca müşterilerle kurdukları yakın ilişkilerin kaybedilmesi anlamına gelir. Ayrıca çıkış mülakatlarının gerçekleştirilmesi için kullanılan kaynaklar, işten ayrılan personelin boşluğunu doldurması istenen geçici işçilere veya fazla mesai yapmak durumunda kalan diğer çalışanlara yapılan ödemeler, yeni işe alım sürecinde reklam, görüşme ve seçim aşamalarında harcanan kaynaklar ve yeni alınan çalışanın eğitimi için yapılan harcamalar da örgütlere yeni maliyetler yaratır (Mitchell, Holtom ve Lee, 2001: 96).

Yetenekli çalışanların örgütler açısından önemi ve bu çalışanların kaybının yarattı̆̆ı maliyet nedeniyle işten ayrılma konusu yoğun şekilde incelenmiş ve bu araştırmalarda çoğunlukla işten ayrılma niyeti üzerinde durulmuştur. İşten ayrılma, bireyin belirli bir kurumdaki istihdamının sona ermesini; işten ayrılma niyeti ise o kurumdan ayrılma konusunda bilinçli bir şekilde isteklilik halini ifade eder (Tett ve Meyer, 1993: 262). 
Yapılan metaanaliz çalışmaları, işten ayrılma niyetinin işten ayrılma davranışının en güçlü yordayıcısı olduğunu ortaya koymuştur (Griffeth, Hom ve Gaertner, 2000; 480; Hom, Caranikas-Walker, Prussia ve Griffeth, 1992: 896). İş tatmini ve bağlılık gibi tutumlar, işten ayrılma sürecinde etkili olan örgütsel tutumlar iken (Cotton ve Tuttle, 1986: 60; Meyer, Stanley, Herscovitch ve Topolnytsky, 2002: 36; Tett ve Meyer, 1993: 279), işten ayrılma niyetinin tutumlar ve işten ayrılma davranışı arasındaki ilişkiye aracılık ettiği kabul edilir (Glissmeyer, Bishop ve Fass, 2008: 460). İşten ayrılma niyeti psikolojik, bilişsel ve davranışsal olarak üç bileşenden oluşan çok aşamalı bir süreçtir. Örgütlerin veya işlerin olumsuz yönlerine gösterilen psikolojik yanıtlar, çalışanların geri çekilme reaksiyonları tetikler ve böylece işten ayrılma reaksiyonunun başlangıç noktasını oluşturur. Devamında beliren bilişsel bileşen ise işten ayrılma niyetinin özünü oluşturur. İşten ayrılma niyeti, davranışın gerçekleşmesi öncesindeki son bilişsel adımdır. Son aşamadaki davranışsal bileşen ise mevcut işten geri çekilmeyi ve iş arayışı gibi gelecekteki fırsatlara yönelik eylemler sergilemeyi içerir (Takase, 2010: 4-5).

İşten ayrılma ile ilgili yapılan araştırmalarda çoğunlukla işten ayrılma niyetinin öncülleri üzerinde durulmuştur. Bu öncüller örgütle ilgili, işle ilgili, çalışanla ilgili ve dişsal faktörler olabilir (Takase, 2010: 6-7). Yapılan araştırmalar gözden geçirildiğinde ödemeler, ödüller ve tanınma, terfi ve büyüme fırsatı, kararlara katılım, iş ve yaşam dengesi, çalışma ortamı, eğitim ve gelişim, liderlik ve iş güvenliği faktörleri çalışan tatmininin sağlanmasını ve elde tutulmasını etkileyen faktörler olarak belirlenmiştir (Das ve Baruah, 2013: 1012). Bunlara ilave olarak zorlayıcı ve ilgi çekici bir iş olması ve yenilikçi düşünme özgürlügünün bulunması da çalışanlarda içsel motivasyon yaratarak elde tutulmalarına katkı sağlar (Samuel ve Chipunza, 2009: 413).

\subsection{Evden Çalışma, İş Yaşamı Kalitesi ve İşten Ayrılma Eğilimi Arasındaki İlişkiler}

Artan rekabet koşulları göz önüne alındığında, örgütler çalışanların ihtiyaçlarına yanıt veren insan kaynakları uygulamalarını benimsemek durumundadır. Bu nedenle, çalışanlar için gittikçe önemli hale gelen iş ve iş dışı yaşam arasında denge ihtiyacının karşılanması amacıyla örgütler tarafından esnek çalışma olanaklarının sunulması gerekmektedir (Dogrul ve Tekeli, 2010: 13). Bilgi teknolojilerinde yaşanan ilerleme sayesinde meydana gelen iş yapma süreçlerindeki bu değişiklikler, bireylerin genel yaşam tarzlarına da yansımaktadır. Evden veya uzaktan çalışma uygulamaları bireylerin işe hazırlık, işe gidiş ve işten dönüş için harcadığı sürelerin ortadan kalkmasını sağlamakta; trafik ve olumsuz hava koşullarına maruz kalmanın önüne geçmekte ve bu süreçlerde yaşadıkları stresi azaltmaktadır (Aksoy, 2012: 402-404). Ayrıca evden çalışma, bireylerin işle ilgili görevleri bireysel ihtiyaç ve isteklerini karşılayacak şekilde organize edebilmelerine olanak sağlar (Golden, 2009: 244). Bu yönleri nedeniyle uzaktan çalışmanın iş yaşamı kalitesi üzerinde pozitif etkisinin olduğu bulunmuştur (Azarbouyeh ve Naini, 2014: 1065-1066). Özellikle salgın sürecinde temel düzeydeki sağlık ve güvenlik ihtiyacı ile ekonomik ve ailevi ihtiyaçların ağır bastığı göz önüne alındığında, evden çalışma sisteminin bu ihtiyaçların karşılanması için avantaj yaratması ve algılanan iş yaşamı kalitesini artırması beklenmektedir.

Öne sürülen tüm avantajlarına rağmen, esnek çalışma düzenlemelerinin işten ayrılma niyeti üzerindeki etkisine ilişkin sonuçlar tutarsızdır. Bazı araştırmalarda (Gajendran ve Harrison, 2007: 1533; McNall vd., 2009: 75) bu düzenlemelerin işten ayırma niyetini azalttı̆̆ını bulunmuştur ancak bir diğer araştırmada (Kossek vd., 2006: 361) aralarında anlamlı ilişki olmadığı görülmüştür. Bu farklılıkların bireylerin esneklik düzenlemelerini nasıl deneyimlediğine ve bu düzenlemeler sayesinde neler elde ettiğine bağlı olduğu düşünülmektedir. Bununla birlikte, evden çalışma düzeninin mevcut salgın döneminde herkes için beliren temel ihtiyaçlara karşılık vereceği düşünüldügünden genel bir avantaj yaratması beklenmektedir. Ayrıca karşılılık ilkesi gereğince (Cropanzano ve Mitchell, 2005: 878), örgütler bireylerin ihtiyaçlarını doyurmalarını sağlayınca bir karşılık bulmaktadır. İşe ve örgüte yönelik tutumlar üzerindeki olumlu etkileri nedeniyle, iş yaşamı kalitesindeki yükselişin tutarlı bir şekilde bireylerin işten ayrılma niyetini azalttı̆ğ bulunmuştur (Altay ve Turunç, 2018: 216; Demir, 2011: 462; Işık ve Başar, 2019: 1084; Turunç vd., 2010: 127; Yıldırım ve Ceyhan, 2020: 1180). Tüm bu nedenlerle salgın döneminde evden çalışan bireylerin, iş yerine gitmeye devam edenlere kıyasla daha yüksek iş yaşamı kalitesi algılaması ve devamında daha düşük işten ayrılma eğilimi göstermesi beklenmektedir. $\mathrm{Bu}$ beklentilere dayalı olarak mevcut araştırmanın hipotezi aşağıdaki şekilde oluşturulmuştur:

Hipotez: Salgıı sürecinde evden çalışma ile işten ayrılma eğilimi arasındaki ilişkide algılanan iş yaşamı kalitesi aracı rol oynar. 


\section{YÖNTEM}

\subsection{Araştırma Modeli}

Araştırmanın amacı çalışanların salgın sürecinde evden çalışması ile işten ayrılma eğilimi arasındaki ilişkide algılanan iş yaşamı kalitesinin aracı rolünün sınanmasıdır. Bu amaçla oluşturulan araştırma modeli Şekil 1'de gösterilmektedir.

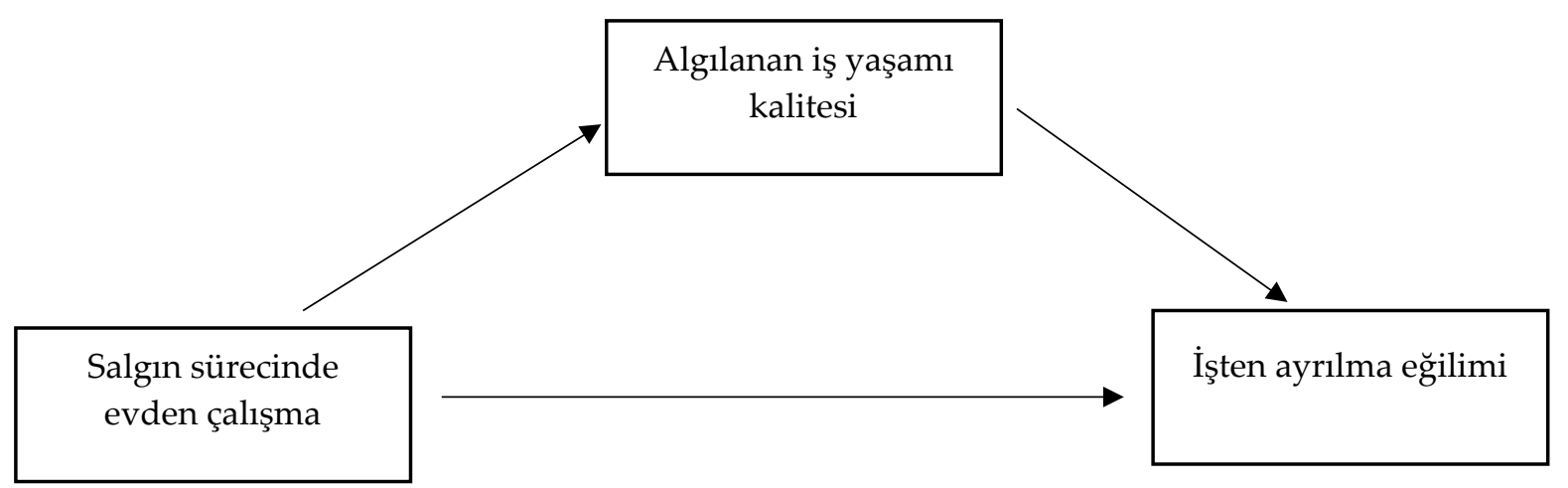

Şekil 1. Araştırmanın modeli

\subsection{Evren ve Örneklem}

Mevcut araştırmanın COVID-19 salgını sürecinde evden veya iş yerlerine giderek çalışmaya devam eden beyaz yakalı çalışanlar ile yürütülmesi amaçlanmıştır. Araştırmanın evrenini İstanbul'da beyaz yakalı olarak çalışan bireyler oluşturmaktadır. Bu doğrultuda, kartopu örnekleme yöntemi ile ulaşılabilen 171'i kadın (\%58.6) ve 121'i erkek (\%41.4) olmak üzere toplam 292 kişi araştırmanın örneklemini oluşturmaktadır. Bu katılımcıların 135'i (\%46.2) salgın öncesinde olduğu gibi iş yerinde çalışmaya devam ederken, 157'si (\%53.8) bu süreçte evden çalışma sistemine geçmiştir. Eğitim düzeyleri incelendiğinde büyük çoğunluğunun lisans (182 kişi, \%62.3) ve yüksek lisans (65 kişi, \%22.3) mezunu olduğu; diğerleri arasında 11 lise (\%3.8), 23 ön lisans (\%7.8) ve 11 doktora (\%3.8) mezunu bulunduğu tespit edilmiştir. Medeni durumları açısından 79'u (\%27.1) evli ve 213'ü (\%72.9) bekar olduğunu bildirmiş ve ortalama yaşları 29.4 olarak bulunmuştur.

\subsection{Veri Toplama Araçları}

Bilgilendirilmiş Onam ve Demografik Bilgi Formu: Soru formunun ilk sayfasında çalışmanın amacına ve içeriğine ilişkin bilgilendirilmiş onam formu sunulmuştur. Bu formun devamında yer alan demografik bilgi kısmında ise cinsiyet, meslek, kurumda çalışma süresine ilişkin sorular yer almaktadır.

Evden Çalışma Durumu: Bireylere çalıştıkları kurumlar tarafından COVID-19 salgını sürecinde evden çalışma imkânı tanınıp tanınmadığına ilişkin bilgi, demografik sorular sonrasında yer alan tek soru ile elde edilmiştir.

İş Yaşamı Kalitesi Ölçeği: Bireylerin iş yaşamı kalitesini sağlık ve güvenlik, ekonomik ve aile, sosyal, saygınlık, kendini gerçekleştirme, bilgi ve estetik ihtiyaçlarının tatmini kapsamında değerlendirmek üzere Sirgy ve arkadaşları (2001: 241-302) tarafından geliştirilen ölçek 16 soruyu içermektedir. Sorular, "1" (Kesinlikle yanlış) ile "7" (Kesinlikle doğru) arasında değişen 7'li likert tipi skalada değerlendirilmektedir. Ölçekten alınan toplam puanın artması iş yaşamı kalitesinin yüksekliğine işaret etmektedir. Bu orijinal ölçeğin güvenirlik katsayısı .78 olarak bildirilmiştir. Ölçeğin Türkçeye uyarlanması Özdemir (2017: 42-50) tarafından yapılmış ve iç tutarlılık katsayısı .94 olarak bulunmuştur. Mevcut çalışmada iş yaşamı kalitesi toplam puan üzerinden analiz edilmiş ve .92 Cronbach alpha katsayısı saptanmıştır.

İşten Ayrılma Niyeti Ölçeği: Çalışanların işten ayrılma niyetlerini ölçmek amacıyla Rosin ve Korabik (1991: 330) tarafından geliştirilen İşten Ayrılma Ölçeği kullanılmıştır. Ölçeğin Türkçe uyarlaması Tanrı̈̈ver (2005: 61-65) tarafından yapılmış ve güvenirlik katsayısı .93 olarak bildirilmiştir. Ölçekte toplamda 4 madde yer almakta ve bu maddelerin puanlanması "1" (Hiç katılmıyorum) ile "5" (Tamamen katılıyorum) arasında değişen $5^{\prime}$ li likert tipi skalada yapılmaktadır. Ölçeğin son maddesi ters kodlanmakta ve ölçekten alınan yüksek 


$$
\text { F. Ayyıldız - D. İ. Çam - Y. Kuş 13/1 (2021) 136-149 }
$$

puan, işten ayrılma niyetinin yüksek olduğunu belirtmektedir. Mevcut çalışma kapsamında ölçeğin iç tutarlılık katsayısı .82 olarak tespit edilmiştir.

\section{4. İşlem}

Sosyal izolasyon önlemi nedeniyle mevcut araştırmanın yüz yüze etkileşimde bulunmadan gerçekleştirilmesi kararlaştırılmış ve bu nedenle veriler internet aracıllı̆ıyla toplanmıştır. Çalışmanın etik izni İstanbul Üniversitesi Sosyal Bilimler Enstitüsü'nden alınmıştır. Veri toplama döneminde sokağa çıkma kısıtlamaları kaldırılmış, örgütlerin belirledikleri politikalara bağlı olarak çalışanlar ya evden ya da ofise giderek çalışmaya devam etmektedir. Kartopu örnekleme yöntemi ile ulaşılabilen kişilere katılımın gönüllülük esasına dayandığı, kimlik bilgilerinin istenmediği ve soruları yanıtlamanın yaklaşık 10 dakika süreceği ifade edilmiştir. Katılmaya gönüllü olan kişilere online soru formuna ilişkin bağlantı linki gönderilmiştir. Verilerin toplanması yaklaşık 3 hafta sürmüştür.

\subsection{Verilerin Analizi}

Araştırmada kullanılan ölçüm araçlarının güvenirliğini test etmek amacıyla her bir ölçeğin Cronbach alpha güvenirlik katsayısı hesaplanmıştır. Değişkenler arasındaki ilişkileri belirleyebilmek amacıyla korelasyon analizi ve ardından da aracı etki olup olmadığını test etmek amacıyla çoklu hiyerarşik doğrusal medyatör regresyon analizi yapılmıştır. Veri analizine başlamadan önce araştırmada yer alan sürekli değişkenlerin normal dağılım gösterip göstermediğini sınamak üzere ölçüm maddelerinin çarpıklık (skewness) ve basıklık (kurtosis) değerleri incelenmiştir.

Çoklu doğrusallık ihlali olup olmadığı ise Tolerans ve Varyans Enflasyon Faktörü (VIF) ile değerlendirilmiş; 0.20-1.00 arasındaki Tolerans değerleri ve 1.00-10.00 arasındaki VIF değerleri çoklu doğrusallık olmadığının kanıtı olarak kabul edilmiştir. Genel kriter sınamaları sonrasında aracılık hipotezinin sınanmasına geçilmiştir. Ancak, bu analiz öncesinde Baron ve Kenny'nin (1986: 1176-1177) aracı etki koşulları dikkate alınmıştır. Bütün veriler SPSS 22.0 paket programıla analiz edilmiştir.

\section{BULGULAR}

Araştırmada yer alan tüm değişkenler arasındaki ilişkileri incelemek için kullanılan Pearson Momentler Çarpımı Korelasyon Katsayısı tekniğinin sonuçları Tablo 1'de sunulmuştur.

Tablo 1. Değişkenler Arasındaki İlişkilere Yönelik Tanımlayıcı İstatistikler ve Pearson Korelasyon Katsayıları

\begin{tabular}{lccccccc}
\hline & Min. & Maks. & Ort. & $S$ & 1 & 2 & 3 \\
\hline 1. Evden Çalışma & - & - & - & - & 1 & $.239^{* *}$ & $-.187^{* *}$ \\
2. İş Yaşamı Kalitesi & 1.6 & 7 & 4.9 & 1.0 & & 1 & $-.564^{* *}$ \\
3. İşten Ayrılma Eğilimi & 1 & 5 & 2.5 & 1.2 & & & 1 \\
\hline
\end{tabular}

** $p<.01$

Tablo 1'deki ilişkiler incelendiğinde tüm değişkenler arasında anlamlı ilişkiler olduğu; evden çalışma ve iş yaşamı kalitesi arasında bu ilişki pozitif yönlü iken, bu değişkenler ile işten ayrılma eğilimi arasındaki ilişkilerin negatif yönlü olduğu görülmektedir.

Araştırmamızın hipotezi doğrultusunda evden çalışma uygulaması ile işten ayrılma eğilimi arasındaki ilişkide iş yaşamı kalitesinin aracı rolünü test edebilmek amacıyla çoklu hiyerarşik doğrusal medyatör regresyon analizi gerçekleştirilmiştir. Analiz öncesinde bu modelde yer alan sürekli değişkenlerin çarpıklık ve basıklık değerlerinin -.47 ile .44 aralığında olması ve vaka sayısının 100'den büyük olması verilerin normal dağıldığını göstermektedir (Tabachnick ve Fidell, 2013: 79-80). Ayrıca bu analizi kullanabilmek amaciyla öncelikle yordayıcı ve aracı değişken arasında çoklu doğrusal ilişki ihlali olup olmadığı tolerans ve VIF değerleri ile sınanmış olup, ilgili değerlerin uygun sınırlar içinde olduğu gözlenmiştir $($ Tolerans $=.94$, VIF $=$ 1.06). Sonrasında Baron ve Kenny'nin (1986: 1176-1177) aracı etki için önerdiği dört aşama takip edilmiştir. 
Buna göre dördüncü aşamadaki aracı etki sınamasını gerçekleştirebilmek için bağımsız değişkenin (evden çalışma), bağımlı değişken (işten ayrılma eğilimi) ve aracı değişken (iş yaşamı kalitesi) üzerindeki etkisinin anlamlı olması gerekmektedir. Ayrıca aracı değişkenin (iş yaşamı kalitesi), bağımlı değişken (işten ayrılma eğilimi) üzerindeki etkisi de anlamlı olmalıdır. İlk adımda yapılan basit doğrusal regresyon analizi sonuçları, evden çalışmanın işten ayrılma niyetindeki değişimin \%3.5'ini anlamlı şekilde açıkladığını göstermiştir $\left(\mathrm{F}_{(1,290)}=10.49, p=.001\right)$. İkinci adımda yapılan basit doğrusal regresyon analizi ise evden çalışmanın iş yaşamı kalitesindeki değişimin \%5.7'sini anlamlı şekilde açıkladığını ortaya koymuştur $\left(\mathrm{F}_{(1,290)}=17.61, p=.000\right)$. Üçüncü adımdaki basit doğrusal regresyon analizi, iş yaşamı kalitesinin işten ayrılma niyetindeki değişimin \%31.8'ini anlamlı düzeyde açıkladığını göstermiştir $\left(\mathrm{F}_{(1,290)}=135.13, p=.000\right)$. Bu sonuçlara göre Baron ve Kenny'nin önerdiği ilk üç kriterin sağlandığı görülmüş ve son aşamada aracı etki sınamasına geçilmiştir. Bu aşamada gerçekleştirilen Çoklu Hiyerarşik Doğrusal Medyatör Regresyon Analizi'nde yordanan değişken olarak işten ayrılma eğilimi, birinci adımda yordayıcı değişken olarak evden çalışma, ikinci adımda ise aracı değişken olarak iş yaşamı kalitesi modele tanıtılmıştır. Elde edilen analiz sonuçları Tablo 2'de sunulmuştur.

Tablo 2. Evden Çalışma ile İşten Ayrılma Eğilimi Arasındaki İlişkide İş Yaşamı Kalitesinin Aracı Etkisine Dair Çoklu Hiyerarşik Doğrusal Medyatör Regresyon Analizi Bulguları

\begin{tabular}{lcccccc}
\hline & $\Delta \mathrm{R}^{2}$ & $\mathrm{~B}$ & $S E$ & $\beta$ & $t$ & $p$ \\
\hline 1. Model & & & & & & \\
Evden Çalışma & .035 & -.39 & .12 & -.19 & -3.24 & .001 \\
\hline 2. Model & & & & & & \\
Evden Çalışma & & -.12 & .10 & -.06 & -1.10 & .271 \\
İş Yaşamı Kalitesi & .286 & 0.50 & .04 & -.55 & -11.03 & .000 \\
\hline
\end{tabular}

Tablo 2 incelendiğinde, birinci modelde evden çalışmanın işten ayrılma eğilimi üzerinde yüksek düzeyde anlamlı bir etkisi olduğu $(\beta=-.19, p=.001)$, iş yaşamı kalitesinin aracı değişken olarak dahil edildiği ikinci modelde ise anlamlılı̆̆ının ortadan kalktığ görülmektedir $(\beta=-.06, p=.271)$. Ayrıca ikinci modelde iş yaşamı kalitesinin, işten ayrılma eğilimi üzerinde yüksek düzeyde etki gösterdiği ortaya çıkmıştır $(\beta=-.55, p=.000)$. $\mathrm{Bu}$ sonuçlara göre, evden çalışma ile işten ayrılma eğilimi arasındaki ilişkide iş yaşamı kalitesinin tam aracı role sahip olduğu kabul edilmiştir.

\section{SONUÇ ve TARTIŞMA}

Mevcut araştırmada, dünya genelinde iş yaşamındaki birçok sektörü olumsuz etkileyen COVID-19 salgınına karşı gerçekleştirilen örgütsel uygulamaların birey ve örgüt düzeyindeki etkilerini incelemek amaçlanmıştır. $\mathrm{Bu}$ doğrultuda evden çalışma sistemine geçilmesi ile bireylerin yaşamlarındaki ihtiyaçları ne düzeyde doyurabildiği ve bu durumun mevcut örgütlerinde devam etme isteklerine nasıl yansıdığı incelenmiştir. Sonuçlar, beklenildiği gibi, evden çalışma sistemine geçen bireylerin temel ve üst düzey ihtiyaçlarını daha çok karşılayabildiğini, diğer bir deyişle algıladıkları iş yaşamı kalitesinin daha yüksek olduğunu ve bu durumun da mevcut işlerinden ayrılma niyetlerinin daha düşük olmasıyla ilişkili olduğunu göstermiştir.

Evden çalışma sistemi yalnızca salgın gibi kriz durumlarında değil olağan durumlarda da sıklıkla benimsenmeye başlanmıştır. Ancak etkinliği konusunda yapılan çalışmalarda tutarlı sonuçlara ulaşılamamıştır (Bloom vd., 2015: 212). Bir yandan iş esnekliği algılayan çalışanların, iş yüküne rağmen iş aile dengesini koruyabildiği (Hill, Hawkins, Ferris ve Weitzman, 2001: 55) ve iş aile çatışmalarının azaldığı bulunmuşken (Choo vd., 2016: 31); diğer yandan bireylerin bu esnek uygulamalar karşısında kendini yükümlü hissetmesi ile iş yoğunlaşmasının meydana geldiği (Kelliher ve Anderson, 2010: 15-16) ve iş yerindekilere kıyasla evde daha uzun saatler çalışan bireylerin iş ve aile dengesini sağlayamadığı ve ilişkilerinde sorunlar yaşayabildiği görülmüştür (Crosbie ve Moore, 2004: 228). Ayrıca iş stresi, tükenme, iş tatminine odaklanılan çalışmalarda da tutarsız sonuçlar elde edilmiştir (Dettmers, Kaiser ve Fietze, 2013: 157). Esnek sistemlerden istenilen sonuçların elde edilememesinin, sosyal ve örgütsel faktörlerin dikkate 
alınmamasına (Jackson ve Van der Wielen, 2002: 5) ve kişisel koşullara bağlı olduğu düşünülmektedir (İşcan ve Naktiyok, 2005: 61). Ancak salgın sürecinde sağlık, güvenlik ve ekonomi konularındaki temel düzey ihtiyaçların ön plana çıkması ile beklenti farklılıklarının azaldığı ve evden çalışma sisteminin bu beklentilere karşılık verdiği düşünülmektedir.

Salgın sosyal temas ile yayılmaya devam etse de bazı çalışanlar örgüt kararları ile iş yerlerine gitmeye devam etmekte, bazıları ise kurumlar faaliyetlerini durduğu için ekonomik zorluk yaşayabilmektedir. Evden çalışmaya geçen bireyler beklentilerin karşılanması açısından tüm bu bireylere kıyasla daha avantajlı görünmektedir. Dolayısı ile normal koşullarda, ev ve iş yaşamı arasındaki sınırların ortadan kalkması bireyler üzerinde farklı etkilerde bulunurken; salgın döneminde önem kazanan ihtiyaçlar ile birlikte evden çalışma sistemine daha olumlu bir bakış açısı gelişmiş olabilir. Ayrıca evden çalışmanın dezavantajları olarak sosyal iletişimin azalması ve yalnızlık hissi ortaya koyulurken (Crosbie ve Moore, 2004: 226), salgın sürecinde izolasyon temel tedbir olduğu için bu durumların algılanışı da farklılaşmış olabilir. Tüm bu gerekçeler, evden çalışmayla birlikte algılanan iş yaşamı kalitesinin de artmasını sağlamıştır.

Çalışanların örgütlerden temel beklentileri arasında yer alan kişisel ve ailevi ihtiyaçlar için zaman tanınması ve çalı̧̧ma ortamının güvenliği (Herriot, Manning ve Kidd, 1997: 156-157) salgın sürecinde daha da önem kazanmakta ve evden çalışma sistemine geçilmesi ile karşılık bulmaktadır. Cropanzano ve Mitchell'e (2005: 878) göre, ilişkilerdeki karşılıklılık kuralı çalışanlar ve örgütler arasında da geçerlidir. Bu açıdan örgütlerin sağladıkları bu imkânlara karşılık olarak bireylerin de örgüt faydasına tutumlar benimsemesi beklenmektedir. Mevcut araştırmada elde edilen sonuçlar, çalışanların işten ayrılma niyeti üzerinden örgütlerin de fayda elde ettiğini göstermektedir. Evden çalışma uygulamasının işveren açısından faydalarını inceleyen önceki çalışmalarda da örgütsel bağlılığ1 (Choo vd., 2016: 31) ve üretkenliği artırdığ1 (Apgar, 1998: 122); ayrıca örgütün daha cazip algılanmasını sağlayarak işten ayrılmaları (Yavuz, 1995: 29) ve devamsızlığı (Possenriede vd., 2014: 15) azalttığı bulunmuştur. Mevcut çalışmanın sonuçları bu bulgular ile tutarlı olmakla birlikte, evden çalışmanın örgütsel etkisinin iş yaşamı kalitesi üzerinden gerçekleşebileceğini göstermektedir. Sonuç olarak, salgın sürecindeki beklentilere karşılık verdiği için olumlu etkileri görülen evden çalışma uygulamasının bu süreç sonrasında da faydalarını koruyabilmek için birey temelli ihtiyaç analizi yapılmalıdır. Evden çalışma ile ihtiyaçları örtüşen kişiler tespit edilerek özellikle bu kişiler için alternatif bir yöntem olarak sunulması gerekmektedir. Bu şekilde uygulandığında, evden çalışma uygulaması, değerli insan kaynağını elde tutmayı ve önemli bir maliyet yaratan işgücü devrini engellemeyi sağlayan bir yatırım olarak görülebilir.

\section{Sınırlılıklar ve Gelecek Çalışmalar İçin Öneriler}

Mevcut araştırma, evden çalışma sisteminin uygulanabilirliği dikkate alınarak farklı meslek gruplarında çalışan beyaz yakalılarla yürütülmüş ancak sektör ve meslek bazlı inceleme yapılmamıştır. Bu sinırlılığı ortadan kaldırmak adına gelecek çalışmalarda bu koşulların etkisinin incelenmesi gerekmektedir. Ayrıca evden çalışma sistemine uygun kişilerin belirlenmesini amacıyla bireysel farklılıkların da incelenmesi katkı sağlayacaktır. Bireylerin ihtiyaçlarını karşılayabilmesinin örgütsel sonuçlar açısından önemli rolü dikkate alınarak, evden çalışma sisteminin bu beklentilere daha iyi cevap verebilecek şekilde nasıl uygulanabileceğinin araştırılması pratik açıdan faydalı olacaktır. 


\section{F. Ayyıldız - D. İ. Çam - Y. Kuş 13/1 (2021) 136-149}

\section{Kaynaklar}

Aksoy, B. (2012). Bilgi teknolojileri ve yeni çalışma ilişkileri. Ege Academic Review, 12(3), 401-414. doi: 10.21121/eab.2012319527

Allen, T. D., Golden, T. D., \& Shockley, K. M. (2015). How effective is telecommuting? Assessing the status of our scientific findings. Psychological Science in the Public Interest, 16(2), 40-68. https://doi.org/10.1177/1529100615593273

Altay, M. \& Turunç, Ö. (2018). İş yükü, çalışma yaşam kalitesi ve işten ayrılma niyeti ilişkisi: Lider-üye etkileşiminin ve örgütsel bağlllığın aracılık rolü, Kafkas Üniversitesi İktisadi ve İdari Bilimler Fakültesi Dergisi, 9(17), 191-229. http://doi.org/10.9775/kauiibfd.2018.009

Apgar, M. (1998). The alternative workplace: Changing where and how people work. Harvard Business Review, 76(3), 121-137.

Avcı, M., \& Yavuz, E. (2020). Çalışanların esnek çalışma düzenlemelerine yönelik tutumlarının işe devamsızlık algıları üzerindeki etkileri: Kamu kurumlarında bir alan araştırması. Yönetim Bilimleri Dergisi, 18(35), 37-55. https://doi.org/10.35408/comuybd.510842

Azarbouyeh, A., \& Naini, S. (2014). A study on the effect of teleworking on quality of work life. Management Science Letters, 4(6), 1063-1068.

Baron, R. M., \& Kenny, D. A. (1986). The moderator-mediator variable distinction in social psychological research: Conceptual, strategic, and statistical considerations. Journal of Personality and Social Psychology, 51(6), 1173-1182.

Been, W. M., den Dulk, L., \& van der Lippe, T. (2016). Dutch top managers and work-life arrangements in times of economic crisis. Community, Work and Family, 19(1), 43-62. https://doi.org/10.1080/13668803.2015.1013019

Bloom, N., Liang, J., Roberts, J., \& Ying, Z. J. (2015). Does working from home work? Evidence from a Chinese experiment. The Quarterly Journal of Economics, 130(1), 165-218. http://doi.org/10.1093/qje/qju032

Centers for Disease Control and Prevention. (2020). Coronavirus disease 2019 (COVID-19), https://www.cdc.gov/coronavirus/2019-ncov/prevent-getting-sick/how-covidspreads.html?CDC_AA_refVal=https\%3A\%2F\%2Fwww.cdc.gov\%2Fcoronavirus\%2F2019ncov\%2Fprepare\%2Ftransmission.html (Erişim tarihi: 15 Eylül 2020).

Choo, J. L. M., Desa, N. M., \& Asaari, M. H. A. H. (2016). Flexible working arrangement toward organizational commitment and work-family conflict. Studies in Asian Social Science, 3(1), 21-36. http://doi.org/10.5430/sass.v3n1p21

Cotton, J. L., \& Tuttle, J. M. (1986). Employee turnover: A meta-analysis and review with implications for research. Academy of Management Review, 11(1), 55-70. doi:10.5465/amr.1986.4282625

Cropanzano, R., \& Mitchell, M. S. (2005). Social exchange theory: An interdisciplinary review. Journal of Management, 31(6), 874-900. http://doi.org/10.1177/0149206305279602

Crosbie, T., \& Moore, J. (2004). Work-life balance and working from home. Social Policy and Society, 3(3), 223233. http://doi.org/10.1017/S1474746404001733

Çakır, O., Doğantan, E., \& Bayar, E. (2018). Otel çalışanlarının örgütsel bağlılıklarını güçlendirmede iş yaşam kalitesinin rolü. Journal of Tourism and Gastronomy Studies, 6(4), 345-359. http://doi.org/10.21325/jotags.2018.313

Çelenk, H., \& Atmaca, M. (2010). Esnek çalışmanın işgücü maliyetlerine ve rekabet gücüne etkisi: Tekstil sektöründe bir uygulama. Yönetim Bilimleri Dergisi, 8(2), 183-202.

Das, B. L., \& Baruah, M. (2013). Employee retention: A review of literature. Journal of Business and Management, 14(2), 8-16. https://doi.org/10.9790/487X-1420816 


$$
\text { F. Ayyıldız - D. İ. Çam - Y. Kuş 13/1 (2021) 136-149 }
$$

Demir, M. (2011). İşgörenlerin çalışma yaşamı kalitesi algılamalarının işte kalma niyeti ve işe devamsızlık ile ilişkisi. Ege Akademik Bakış Dergisi, 11(3), 453-464.

Dettmers, J., Kaiser, S., \& Fietze, S. (2013). Theory and practice of flexible work: Organizational and individual perspectives. Introduction to the special issue. Management Revue, 24(3), 155-161. http://doi.org/10.5771/0935-9915-2013-3-155

Doğrul, B. Ş., \& Tekeli, S. (2010). İş-yaşam dengesinin sağlanmasında esnek çalışma. Sosyal ve Beşeri Bilimler Dergisi, 2(2), 11-18.

Efraty, D., \& Sirgy, M. J. (1990). The effects of quality of working life (QWL) on employee behavioral responses. Social Indicators Research, 22(1), 31-47. http://doi.org/10.1007/BF00286389

Erdem, M. (2010). Öğretmen algılarına göre liselerde iş yaşamı kalitesi ve örgütsel bağlllıkla ilişkisi. Kuram ve Uygulamada Ĕ̆itim Yönetimi, 4(4), 511-537.

Farnham, P. G. (1994). Defining and measuring the costs of the HIV epidemic to business firms. Public Health Reports, 109(3), 311-318.

Gajendran, R. S., \& Harrison, D. A. (2007). The good, the bad, and the unknown about telecommuting: Metaanalysis of psychological mediators and individual consequences. Journal of Applied Psychology, 92(6), 1524-1541. https://doi.org/10.1037/0021-9010.92.6.1524

Glissmeyer, M., Bishop J. W., \& Fass, R. D. (2008). Role conflict, role ambiguity and intention to quit the organization: The case of law enforcement. Academy of Management Journal, 40(1), 82-111.

Golden, T. D. (2009). Applying technology to work: Toward a better understanding of telework. Organization Management Journal, 6(4), 241-250. https://doi.org/10.1057/omj.2009.33

Griffeth, R. W., Hom, P. W., \& Gaertner, S. (2000). A meta-analysis of antecedents and correlates of employee turnover: Update, moderator tests, and research implications for the next millennium. Journal of Management, 26(3), 463-488. https://doi.org/10.1016/S0149-2063(00)00043-X

Herriot, P., Manning, W. E. G., \& Kidd, J. M. (1997). The content of the psychological contract. British Journal of Management, 8(2), 151-162. http://doi.org/10.1111/1467-8551.0047

Hill, E. J., Hawkins, A. J., Ferris, M., \& Weitzman, M. (2001). Finding an extra day a week: The positive influence of perceived job flexibility on work and family life balance. Family Relations, 50(1), 49-58. http://doi.org/10.1111/j.1741-3729.2001.00049.x

Hobbs, D. \& Armstrong, J. (1998). An Experimental Study of Social and Psychological Aspects of Teleworking, Facilities, 16(12-13), 366-371. https://doi.org/10.1108/02632779810235744

Homeland Security Council (US). (2006). National Strategy for Pandemic influenza: Implementation Plan, https://www.cdc.gov/flu/pandemic-resources/pdf/pandemic-influenza-implementation.pdf (Erişim tarihi: 15 Eylül 2020).

Hom, P. W., Caranikas-Walker, F., Prussia, G. E., \& Griffeth, R. W. (1992). A meta-analytical structural equation analysis of a model of employee turnover. Journal of Applied Psychology, 77(6), 890-909. https://doi.org/10.1037/0021-9010.77.6.890

Horst, D. J., Broday, E. E., Bondarick, R., Serpe, L. F., \& Pilatti, L. A. (2014). Quality of working life and productivity: An overview of the conceptual framework. International Journal of Managerial Studies and Research, 2(5), 87-98.

Hotopp, U. (2002). Teleworking in the UK. Labour Market Trends, 110(6), 311-318.

Huang, T. C., Lawler, J., \& Lei, C. Y. (2007). The effects of quality of work life on commitment and turnover intention. Social Behavior and Personality: An International Journal, 35(6), 735-750. https://doi.org/10.2224/sbp.2007.35.6.735

Işık, M. F., \& Başar, M. S. (2019). İş yaşam kalitesinin işten ayrılma niyeti üzerindeki rolü: Erzurum ili Palandöken Kış Turizmi Merkezi'ndeki çalışanlar üzerinde bir uygulama. Journal of International Social Research, 12(66). 1074-1085. http://doi.org/10.17719/jisr.2019.3653 


$$
\text { F. Ayyıldız - D. İ. Çam - Y. Kuş 13/1 (2021) 136-149 }
$$

Ives, J., Greenfield, S., Parry, J. M., Draper, H., Gratus, C., Petts, J. I. ..., Wilson, S. (2009). Healthcare workers' attitudes to working during pandemic influenza: A qualitative study. BMC Public Health, 9(1), 56-68. http://doi.org/10.1186/1471-2458-9-56

İşcan, Ö. F., \& Naktiyok, A. (2005). Attitudes towards telecommuting: the Turkish case. Journal of Information Technology, 20(1), 52-63. http://doi.org/10.1057/palgrave.jit.2000023

Jackson, P. J., \& van der Wielen, J. M. (2002). Actors, approaches and agendas: from telecommuting to the virtual organisation. In P. J. Jackson \& J. M. van der Wielen (Eds.), Teleworking: International perspectives: From telecommuting to the virtual organisation (pp. 1-17), London and New York: Routledge.

Kalleberg, A. L., \& Vaisey, S. (2005). Pathways to a good job: Perceived work quality among the machinists in North America. British Journal of Industrial Relations, 43(3), 431-454. https://doi.org/10.1111/j.14678543.2005.00363.x

Kelliher, C., \& Anderson, D. (2010). Doing more with less? Flexible working practices and the intensification of work. Human Relations, 63(1), 83-106. http://doi.org/10.1177/0018726709349199

Kiernan, W. E., \& Knutson, K. (1990). Quality of work life. In R. L. Schalock \& M. J. Begab (Eds.), Quality of life: Perspectives and issues (pp. 101-114), Washington: American Association Mental Retardation.

Kossek, E. E., Lautsch, B. A., \& Eaton, S. C. (2006). Telecommuting, control, and boundary management: Correlates of policy use and practice, job control, and work-family effectiveness. Journal of Vocational Behavior, 68(2), 347-367. https://doi.org/10.1016/j.jvb.2005.07.002

Lazar, I., Osoian, C., \& Ratiu, P. (2010). The role of work-life balance practices in order to improve organizational performance. European Research Studies, 13(1), 201-214.

Lewis, S. (2003). Flexible working arrangements: Implementation, outcomes, and management. International Review of Industrial and Organizational Psychology, 18, 1-28. http://doi.org/10.1002/0470013346.ch1

McNall, L. A., Masuda, A. D., \& Nicklin, J. M., (2009). Flexible work arrangements, job satisfaction, and turnover intentions: The mediating role of work-to-family enrichment, The Journal of Psychology: Interdisciplinary and Applied, 144(1), 61-81. http://doi.org/10.1080/00223980903356073

Meyer, J. P., Stanley, D. J., Herscovitch, L., \& Topolnytsky, L. (2002). Affective, continuance, and normative commitment to the organization: A meta-analysis of antecedents, correlates, and consequences. Journal of Vocational Behavior, 61(1), 20-52.

Mitchell, T. R., Holtom, B. C., \& Lee, T. W. (2001). How to keep your best employees: Developing an effective retention policy. Academy of Management Perspectives, 15(4), 96-108. https://doi.org/10.5465/AME.2001.5897929

Nanjundeswaraswamy, T. S., \& Swamy, D. R. (2013). Review of literature on quality of work life. International Journal for Quality Research, 7(2), 201-214.

Near, J. P., Rice, R. W., \& Hunt, R. G. (1980). The relationship between work and nonwork domains: A review of empirical research. Academy of Management Review, 5(3), 415-429. http://doi.org/10.2307/257117

Occupational Safety and Health Act (2020). Guidance on preparing workplaces for COVID-19, https://www.osha.gov/Publications/OSHA3990.pdf (Erişim tarihi: 15 Eylül 2020).

Osnowitz, D. (2005). Managing time in domestic space: Home-based contractors and household work. Gender and Society, 19(1), 83-103. http://doi.org/10.1177/089124204270209

Özdemir, E. N. (2017). The association between employees' perception of three socio-cultural dimensions, quality of work life and psychological well-being (Yayımlanmamış Yüksek Lisans Tezi). Yeditepe Üniversitesi Sosyal Bilimler Enstitüsü, İstanbul.

Öztürk Çiftci, D. \& Parlak, N. (2019). Çalışanların iş yaşam kalitesi algıları ile motivasyonları arasındaki ilişkinin incelenmesi: Muhasebe meslek elemanları üzerine bir uygulama, Business $\mathcal{E}$ Management Studies: An International Journal, 7(2), 687-713. http://doi.org/10.15295/bmij.v7i2.1042 


$$
\text { F. Ayyıldız - D. İ. Çam - Y. Kuş 13/1 (2021) 136-149 }
$$

Possenriede, D. S., Hassink, W. H. J., \& Plantenga, J. (2014). Does temporal and locational flexibility of work reduce absenteeism?. Discussion Paper Series/Tjalling C. Koopmans Research Institute, 14(09), 1-32.

Reilly, P. A. (2001). Flexibility at work: Balancing the interests of employer and employee. England: Gower Publishing.

Rintala, N. \& Suolanen, S. (2005). The implications of digitalization for job descriptions, competencies and the quality of working life. Nordicom Review, 26(2), 53-67.

Rosin, H. M., \& Korabik, K. (1991). Workplace variables, affective responses, and intention to leave among women managers. Journal of Occupational Psychology, 64(4), 317-330. https://doi.org/10.1111/j.20448325.1991.tb00563.x

Samuel, M. O., \& Chipunza, C. (2009). Employee retention and turnover: Using motivational variables as a panacea. African Journal of Business Management, 3(9), 410-415. https://doi.org/10.5897/AJBM09.125

Sarbu, M. (2018). The role of telecommuting for work-family conflict among German employees. Research in Transportation Economics, 70, 37-51. https://doi.org/10.1016/j.retrec.2018.07.009

Sardeshmukh, S. R., Sharma, D., \& Golden, T. D. (2012). Impact of telework on exhaustion and job engagement: A job demands and job resources model. New Technology, Work \& Employment, 27, 193-207. doi:10.1111/j.1468- 005X.2012.00284

Sennett, R. (2010). Karakter Aşınması. (B. Yıldırım, Çeviri Ed.), İstanbul: Ayrıntı Yayınları.

Shamir, B., \& Salomon, I. (1985). Work-at-home and the quality of working life. Academy of Management Review, 10(3), 455-464. http://doi.org/10.2307/258127

Shockley, K. M., \& Allen, T. D. (2007). When flexibility helps: Another look at the availability of flexible work arrangements and work-family conflict. Journal of Vocational Behavior, 71(3), 479-493. https://doi.org/10.1016/j.jvb.2007.08.006

Sinha, C. (2012). Factors affecting quality of work life: Empirical evidence from Indian organizations. Australian Journal of Business and Management Research, 1(11), 31-40.

Sirgy, M. J., Efraty, D., Siegel, P., \& Lee, D. J. (2001). A new measure of quality of work life (QWL) based on need satisfaction and spillover theories. Social Indicators Research, 55(3), 241-302. http://doi.org/10.1023/A:1010986923468

Song, Y., \& Gao, J. (2020). Does telework stress employees out? A study on working at home and subjective well-being for wage/salary workers. Journal of Happiness Studies, 21(7), 2649-2668. https://doi.org/10.1007/s10902-019-00196-6

Stavrou, E. T. (2005). Flexible work bundles and organizational competitiveness: a cross-national study of the European work context. Journal of Organizational Behavior: The International Journal of Industrial, Occupational and Organizational Psychology and Behavior, 26(8), 923-947. https://doi.org/10.1002/job.356

Sturgeon, A. (1996). Telework: Threats, risks and solutions. Information Management and Computer Security, 4(2), 27-38. http://doi.org/10.1108/09685229610121017

Tabachnick, B. G., \& Fidell, L. S. (2013). Using Multivariate Statistics (Vol. 6). Boston, MA: Pearson.

Takase, M. (2010). A concept analysis of turnover intention: Implications for nursing management. Collegian, 17(1), 3-12. https://doi.org/10.1016/j.colegn.2009.05.001

Tanrı̈ver, Ü. (2005). The effects of learning organization climate and self directed learning on job satisfaction, affective commitment and intention to turnover (Yayımlanmamış Yüksek Lisans Tezi). Marmara Üniversitesi Sosyal Bilimler Enstitüsü, İstanbul.

Tett, R. P., \& Meyer, J. P. (1993). Job satisfaction, organizational commitment, turnover intention, and turnover: path analyses based on meta-analytic findings. Personnel Psychology, 46(2), 259-293. https://doi.org/10.1111/j.1744-6570.1993.tb00874.x 
F. Ayyıldız - D. İ. Çam - Y. Kuş 13/1 (2021) 136-149

Turunç, Ö., Tabak, A., Şeşen, H., \& Türkyılmaz, A. (2010). Çalışma yaşamı kalitesinin prosedür adaleti, iş tatmini, iş stresi ve işten ayrılma niyetine etkisi. ISGUC The Journal of Industrial Relations and Human Resources, 12(2), 115-134. https://doi.org/10.4026/1303-2860.2010.0146.x

Van der Lippe, T., \& Lippényi, Z. (2020). Beyond formal access: Organizational context, working from home, and work-family conflict of men and women in European workplaces. Social Indicators Research, 151, 383-402. https://doi.org/10.1007/s11205-018-1993-1

World Health Organization. (2020a). WHO Director-General's opening remarks at the media briefing on COVID-19 - 11 March 2020, https://www.who.int/dg/speeches/detail/who-director-general-sopening-remarks-at-the-media-briefing-on-covid-19---11-march-2020 (Erişim tarihi: 15 Eylül 2020).

World Health Organization. (2020b). Coronavirus disease (COVID-19) advice for the public, https://www.who.int/emergencies/diseases/novel-coronavirus-2019/advice-for-public (Erişim tarihi: 15 Eylül 2020).

World Health Organization. (2020c). Getting your workplace ready for COVID-19, https://www.who.int/docs/default-source/coronaviruse/getting-workplace-ready-for-covid19.pdf?sfvrsn=359a81e7_6 (Erişim tarihi: 15 Eylül 2020).

Yavuz, A. (1995). Esnek Çalışma ve Endüstri İlişkilerine Etkisi, İstanbul: Filiz Kitabevi.

Yıldırım, M., \& Ceyhan, S. (2020). Çalışma yaşam kalitesinin işten ayrılma niyetine etkisinde örgütsel sinizmin aracilık rolü. Anemon Muş Alparslan Üniversitesi Sosyal Bilimler Dergisi, 8(4), 1175-1184. http://doi.org/10.18506/anemon.643845

Yılmaz, A., \& Tanrıverdi, H. (2017). Örgütsel destek algısı üzerinde iş yaşam kalitesinin rolü: Beş yıldızlı otel aşçları üzerine ampirik bir araştırma. International Journal of Management And Administration, 1(2), 83105. https://doi.org/10.29064/ijma.343213

Zhang, S. X., Wang, Y., Rauch, A., \& Wei, F. (2020). Unprecedented disruption of lives and work: Health, distress and life satisfaction of working adults in China one month into the COVID-19 outbreak. Psychiatry Research, 288, 112958. 1-6. https://doi.org/10.1016/j.psychres.2020.112958 